\title{
PAULO EMÍlio SALLES GOMES E A TRANSFORMAÇÃO DE CRÔNICAS EM UMA HISTÓRIA DO CINEMA BRASILEIRO: OS CASOS DO NASCIMENTO E DA BELA ÉPOCA
}

\author{
PAULO EMILIO SALLES GOMES AND PROCESSING IN A CHRONIC \\ HISTORY OF BRAZILIAN CINEMA: THE CASES OF BIRTH AND \\ BEAUTIFUL EPOCH
}

\begin{abstract}
RESUMO: Procuraremos demonstrar como o crítico e historiador do cinema brasileiro Paulo Emílio Salles Gomes, na obra Panorama do cinema brasileiro: 1896/1966 (1966), promoveu a transposição de crônicas do cinema brasileiro para uma história de nossa atividade cinematográfica, sobretudo com relação ao tema do nascimento do cinema brasileiro e ao conceito de Bela época aplicado a determinado período de nossa história cinematográfica.
\end{abstract}

PALAVRAS-CHAVE: História. Cinema brasileiro. Nascimento. Bela época.

\begin{abstract}
We seek to show how the critic and historian of brazilian cinema Paulo Emilio Salles Gomes, in the work of Brazilian cinema overview: 1896/1966 (1966), promoted the implementation of chronic Brazilian cinema for a history of our cinematic activity, especially with respect to the theme birth of Brazilian film and the concept of Beautiful epoch applied to particular period of our cinematic history.
\end{abstract}

KEYWORD: History. History of Brazilian cinema. Birth. Beautiful epoch.

\begin{abstract}
A representação - mise em scène literária - não é histórica senão quando articulada com um lugar social da operação científica e quando institucional e tecnicamente ligada a uma prática do desvio, com relação aos modelos culturais ou teóricos contemporâneos.

Michel de Certeau, in: A escrita da história.
\end{abstract}

As considerações de Michel de Certeau são de grande valia aos nossos propósitos nesse artigo. Tecidas após o historiador francês discutir as inúmeras influências do lugar social e da prática de pesquisa na operação historiográfica, elas nos demonstram que uma narrativa pode ser considerada histórica se for articulada com um lugar social e uma prática científica (CERTEAU, 2007, p. 93-94). A partir dessa premissa, conforme Certeau, o discurso 
histórico "[...] se situa fora da experiência que lhe confere crédito; [...] se dissocia do tempo que passa, esquece o escoamento dos trabalhos e dos dias, para fornecer 'modelos' no quadro fictício do tempo passado" (CERTEAU, 2007, p. 95), e, por esse motivo: já não corresponde mais à prática de pesquisa (experiência). Com base nessa asserção, o autor enfatiza:

O "Cahier rouge" de Claude Bernard (1850-1860) representa uma crônica já distante da experiência efetiva em laboratório, e a teoria, a Introduction à l'étude de la médecine expérimentale (1865) é, por sua vez, decalada, simplificadora e redutora com relação ao "Cahier". Entre milhares de outros, este exemplo mostra a passagem da prática à crônica e da crônica à didática. Só uma distorção permite a introdução da "experiência" numa outra prática, igualmente social, mas simbólica, escrituraria, que substitui a autoridade de um saber pelo trabalho de uma pesquisa (CERTEAU, 2007, p. 96).

Nota-se que somos alertados com um exemplo das ciências naturais - o que nos soa ainda mais caro - para o fato de que em nosso procedimento de trabalho existe uma distância considerável entre a prática efetivamente experimentada e a representação literária que fazemos dela. No trabalho do pesquisador em história, portanto, num primeiro instante existe a prática (experiência), posteriormente a passagem dessa prática à crônica dos ocorridos e, por fim, a transposição dessa crônica a uma didática (escrita) (CERTEAU, 2007, p. 96).

Nesse ponto de sua reflexão, Certeau salienta que no empreendimento da escrita historiográfica, caracterizadora do trabalho histórico como híbrido - constituído tanto de "efeito de real" quanto de construção literária —, o discurso histórico pretende dar um conteúdo verdadeiro (que vem da verificabilidade e do discurso lógico fragmentado) sob a forma de uma narração (CERTEAU, 2007, p. 96). Assim, manifesta-se uma construção desdobrada na qual esse discurso histórico misto (junção de discurso lógico fragmentado e narração) vai se construindo de acordo com dois movimentos contrários: o da narrativização — procedimento mediante o qual se passa do conteúdo à sua expansão, ou seja, de modelos narrativos acrônicos a uma cronologização ou de uma doutrina a uma manifestação de tipo narrativo - e da semantização - edificação de um sistema de sentido em que o material passa dos elementos descritivos a um encadeamento sintagmático e à constituição de sequências históricas programadas (CERTEAU, 2006, p. 100-101).

Depreende-se dessas asserções que, mediante o movimento de narrativização, a prática/experiência recebe uma cronologia, transformando-se em uma crônica, que pelo movimento de semantização passa da simples descrição de elementos ordenados temporalmente a um sistema encadeado de sentido: em uma narrativa convincente. Portanto, os movimentos contrários de narrativização e semantização promovem, tanto a passagem de

Oficina do Historiador, Porto Alegre, EDIPUCRS, v. 7, n. 2, jul./dez. 2014, p. 118-139. 
gêneros quanto a passagem da simples causalidade para a sucessividade, representando relações de coexistência com relações de coerência. Entretanto, de acordo com Certeau, tais procedimentos não são efetuados de maneira descompromissada por parte do historiador, pois no relacionamento interno do discurso - cuja pretensão do remetente é que ele seja historiográfico - com os dados presentes na crônica, o primeiro é edificado com base em postulados epistemológicos que vêm da semantização referencial que surge da própria cultura em que o historiador está inserido, da transcritibilidade das linguagens já codificadas nessa mesma cultura e da possibilidade de construir uma metalinguagem na própria língua dos documentos utilizados (CERTEAU, 2007, p. 100-102).

À luz dessas considerações de ordem teórica, visamos demonstrar que o crítico e historiador do cinema brasileiro Paulo Emílio Salles Gomes ${ }^{1}$, com o ensaio Panorama do cinema brasileiro: 1896/1966 (1966) $)^{2}$ — um dos textos que compõem a historiografia clássica do cinema nacional ${ }^{3}$ - , promove a transposição de crônicas do cinema brasileiro para uma história de nossa atividade cinematográfica, sobretudo com relação ao tema do nascimento do cinema brasileiro e ao conceito de Bela época ${ }^{4}$. Em outros termos, procuramos evidenciar que o crítico, quando urde sua síntese histórica sobre o cinema brasileiro, utiliza

\footnotetext{
${ }^{1}$ Paulo Emílio (1916-1977) foi militante comunista na juventude, motivo pelo qual foi preso político do governo Getúlio Vargas em 1937. Na década de 1940, juntamente com Antônio Candido, Décio de Almeida Prado, Lourival Gomes Machado, Rui Coelho, Gilda de Mello Souza e Alfredo Mesquita compôs o grupo que editou e colaborou na seminal revista Clima, cujas análises de linguagens artísticas modificaram os rumos da crítica cultural do país. Nos anos de 1950 e 1960, após quase vinte primaveras residindo na França, Paulo Emílio tornou-se o principal articulista de cinema do país pelas páginas do Suplemento Literário de O Estado de São Paulo, um dos fundadores e curador-chefe da Cinemateca Brasileira, um dos fundadores e professor do curso de cinema da Universidade de Brasília (UnB) e da Escola de Comunicações e Artes da Universidade de São Paulo (ECA-USP), além de professor da Faculdade de Filosofia, Letras e Ciências Humanas (FFLCH), também da USP.

${ }^{2}$ Editado originalmente pela editora Expressão e Cultura, em 1966, com o nome 70 anos de cinema brasileiro, e reeditado, primeiro em 1970 pela ECA-USP, versando Panorama do Cinema brasileiro: 1896/1966, e posteriormente, em 1980, na coletânea de ensaios de Paulo Emílio intitulada Cinema: trajetória no subdesenvolvimento. Utilizamos essa última versão, cf. (GOMES, 1980, p. 35-79).

${ }^{3}$ Ao nos referirmos à historiografia clássica do cinema nacional fazemos menção às obras pertinentes ao cinema brasileiro urdidas na década de 1950 e 1960, especialmente Introdução ao cinema brasileiro (1959), de Alex Viany, e Panorama do cinema brasileiro: 1896/1966 (1966), de Paulo Emílio Salles Gomes. Para tal projeção, tomamos como ponto de partida a publicação Historiografia clássica do cinema brasileiro (1995), de JeanClaude Bernardet, cf. (BERNARDET, 1995).

${ }^{4} \mathrm{O}$ tema do nascimento, desde as primeiras investigações sobre nossa história cinematográfica, transformou-se numa obsessão por parte dos estudiosos do cinema brasileiro. Entre inúmeras controvérsias, a partir do Panorama do cinema brasileiro: 1896/1966, escrito por Paulo Emílio, em 1966, o nascimento do cinema brasileiro passou a ser datado em 1898, como efeito de uma filmagem da Baía de Guanabara no Rio de Janeiro efetuada pelo imigrante italiano Afonso Segreto. A Bela época do cinema brasileiro é atribuída à harmonia da tríade produção-exibição-público no período de 1907-1911 por parte de Paulo Emílio em seu Panorama do cinema brasileiro: 1896/1966. Consideramos a Bela época do cinema brasileiro um conceito tomando de empréstimo as considerações do teórico alemão Jörn Rüsen. De acordo com ele: "Os conceitos são 'históricos' quando na designação dos estados de coisas se referem à 'história' como a suprassumo do que está sendo designado. [...] exprimem, explícita ou implicitamente, a qualidade temporal de estados de coisas do passado humano, qualidade que esses estados de coisas possuem numa determinada relação de sentido e significado com o presente e o futuro" (RÜSEN, 2010, p. 92).
}

Oficina do Historiador, Porto Alegre, EDIPUCRS, v. 7, n. 2, jul./dez. 2014, p. 118-139. 
dados e informações presentes em crônicas sobre nossa atividade cinematográfica para edificar um sistema de sentido em sua narrativa que a caracteriza como história e, simultaneamente desvela o caráter de crônica das obras anteriores - A saber: Pequena história do cinema brasileiro (1955), de Francisco Silva Nobre, e Introdução ao cinema brasileiro (1959), de Alex Viany ${ }^{5}$.

\title{
As crônicas atinentes ao cinema brasileiro: o nascimento e a Bela época
}

Os estudos de cinema no Brasil e as preocupações com a história do cinema brasileiro foram potencializados na década de 1950. Embora já houvessem alguns Cineclubes, Companhias Cinematográficas e revistas especializadas na Sétima Arte, somente a partir de meados do século XX ocorreu um envolvimento mais efetivo de intelectuais, críticos e cineastas brasileiros com a pesquisa sobre a Sétima Arte nacional.

Nesta ambiência foi publicado o opúsculo Pequena história do cinema brasileiro, de Francisco Silva Nobre. Em linhas gerais, a obra possui uma "introdução", na qual Nobre expõe algumas de suas perspectivas, um "corpo do trabalho", que se fundamenta em um apanhado cronológico do cinema brasileiro até 1955 (ano de publicação da obra), e uma "conclusão", na qual os pontos de vista do autor são demonstrados. Mais expressiva ainda para o nosso propósito inicial é uma espécie de apresentação de seu trabalho, em que Nobre deixa bem claras as suas intenções, pontuando:

\begin{abstract}
Ainda não foi escrita a história do Cinema Brasileiro; o presente opúsculo não pretende preencher essa lacuna, mas, apenas, relembrar, de maneira sucinta, alguns momentos de nossa evolução cinematográfica. Não procuramos fazer trabalho de análise, limitando-nos à apresentação de dados colhidos nas parcas fontes de que dispomos para estudar o assunto. Excusamos-nos, por isso, das falhas e omissões em que incorremos (NOBRE, 1955, p. 5).
\end{abstract}

As palavras do autor não deixam espaço para dúvidas, pois não é sua intenção escrever uma história do cinema nacional, mas sim relembrar sucintamente "alguns momentos".

\footnotetext{
${ }^{5}$ Com base nessa predisposição, acreditamos ser possível perceber um dos motivos pelos quais Panorama do cinema brasileiro: 1896/1966 se constituiu em matriz interpretativa da história do cinema brasileiro. A discussão dessa matriz não será efetuada neste artigo, sobretudo devido a espaço para redação. Em função disso, apenas sugerimos uma leitura, cf. (MORAIS, 2010a).
} 
Apesar de conter certo nacionalismo, bem como tecer severas críticas ao domínio do mercado brasileiro pelas fitas americanas e ao papel do Estado nacional brasileiro nesse processo que, segundo Nobre, devia concentrar sua atuação na criação de leis protecionistas em favor de nosso cinema e no auxílio financeiro a empresas nacionais - , a obra de Nobre não passa de um apanhado cronológico de "alguns momentos" do cinema nacional.

Malgrado articular dados informativos sobre exibição pública dos filmes, produção e crítica cinematográfica, assim como apresentar nas linhas mestras algumas discussões que giram em torno da industrialização de nosso cinema, do consequente papel do Estado nesse contexto e da luta polarizada entre filmes nacionais e filmes estrangeiros (SÁ NETO, 2003, p. 146-149), de modo geral o empreendimento de Silva Nobre, por um lado, é parco em explicações e carregado de lacunas com relação à interpretação das informações e, por outro, mantém uma rígida e compacta cronologia dos eventos do cinema brasileiro na ordem sucessiva de suas ocorrências, sem hierarquizar nenhum tipo de evento.

Em vista disso, Pequena história do cinema brasileiro pode ser considerada uma crônica de eventos ligados ao cinema brasileiro. Esta característica de crônica do empreendimento de Francisco Silva Nobre fica mais explícita quando adentramos ao mote do nascimento do cinema brasileiro e ao conceito de Bela época, atribuído a determinado período de nossa cinematografia.

No que toca ao nascimento, cuja datação canônica é 1898 e plasmada em uma filmagem da Baía da Guanabara, no Rio de Janeiro, Silva Nobre sequer utiliza o termo. Após a seção "Antecedentes históricos", na qual delineia uma sintética cronologia de acontecimentos demonstrativos do interesse das civilizações em projetar imagens, bem como faz referência às primeiras projeções do cinematógrafo na França e no Brasil, o autor adentra a seção "O primeiro giro da manivela", salientando no primeiro parágrafo:

No dia 5 de novembro de 1903, o português Antonio Leal realizou os primeiros movimentos de câmara cinematográfica no Brasil, filmando cenas naturais na Avenida Central (hoje, Rio Branco). Há dúvidas, porém, quanto ao ano em que isso se deu, pois temos lido referências, também, a $1902 \mathrm{e}$ 1905. A data foi, por esse motivo, proclamada como o "Dia do cinema brasileiro" (NOBRE, 1955, p. 12).

Notadamente esse é o mais próximo que Silva Nobre chega de apontar uma primeira filmagem em solo nacional. De todo modo, o suposto nascimento do cinema nacional não surge como elemento norteador de sua crônica, tampouco é mencionado. Ademais, ainda fica 
a dúvida lançada pelo próprio autor acerca da datação correta, pois o ano de 1903 aparece como uma possibilidade, porém acompanhando de outras duas: o ano de 1902 e o de 1905.

A respeito do conceito de Bela época, o pesquisador também não utiliza o termo. Ao argumentar sobre o período de 1907 a 1911, recorte canonizado na historiografia clássica do cinema nacional como sendo a Bela época, Nobre apenas menciona cronologicamente alguns acontecimentos. Em 1907 são localizados, além da película Os estranguladores, realizada por Antonio Leal e dirigida por Marzullo, o importante papel de Francisco Serrador na produção de cerca de meia centena de filmes falantes (sem citá-los), e a inauguração dos Cinematógrafos Parisiense, Pathé e Ouvidor, todos no Rio de Janeiro. Em 1908, o autor menciona uma película de Paulo Benedetti rodada em Minas Gerais e diversas inaugurações de salas de exibição no Rio de Janeiro. No ano de 1909, mais salas na capital federal recebem alusão, bem como Paz e Amor, de José do Patrocínio Filho, é considerada "a mais conhecida fita de nosso primitivo cinema" (NOBRE, 1955, p. 15). Em 1910, Francisco Serrador constitui o nome de destaque, pois o pesquisador ressalta sua importância na inauguração de salas de exibição em cerca de 150 cidades do interior paulista graças a mudança do comerciante para o estado bandeirante. Curiosamente, 1911 não entra na cronologia efetuada por Silva Nobre, que a ignora e salta para 1912, ano no qual Roquette Pinto é a única figura citada, sobretudo por capturar cenas do cotidiano de índios da tribo Nambikuara e projetá-las em reuniões culturais.

É bastante curioso: a reportagem cronológica de Silva Nobre, abordando tanto o ano de 1907 quanto o ano de 1911, marcos do recorte Bela época, sequer menciona o ano de 1911, tampouco faz alusão a algum tipo de acontecimento de maior vulto, seja para aumentar ou diminuir quantitativamente as produções, exibições ou distribuição cinematográfica no Brasil. O período é percorrido sem nenhuma euforia ou realce quanto a algum tipo de "boom" da atividade cinematográfica nacional. $\mathrm{Na}$ verdade, esse melhor desempenho do cinema brasileiro na cronologia de Silva Nobre parece ocorrer em 1913 - datação excluída do que se convencionou chamar de Bela época do cinema brasileiro - , pois o autor ratifica:

Irradia-se por todos os pontos do território brasileiro o trabalho de nossos primitivos cineastas; não se limitaram eles a filmar no Rio e São Paulo, onde se localizam os primeiros arremedos de estúdios e laboratórios. Pode-se notar a existência de conhecimento de nossas amplas possibilidades no terreno cinematográfico e procura-se aproveitar, em "shorts" e documentários a respeito de nossa economia, de nossa cultura, de nossa vida, enfim, o que melhor propaganda possa fazer de nossa gente e de nossa terra (SILVA NOBRE, 1955, p. 16). 
Nota-se que Silva Nobre não aventa explicação para tal "irradiação" do trabalho cinematográfico nacional, como também não enquadra a dita proliferação do cinema em solo brasileiro no interior do recorte canonizado, que vai de 1907 a 1911. Do mesmo modo, tal recorte clássico é estendido, quando o autor trabalha com a tese de um suposto colapso da atividade cinematográfica nacional com o início da Primeira Guerra Mundial (1914-1918), do seguinte modo:

O grande conflito que envolvia toda a Europa desde 1914 havia de escrever uma página nova na história do Cinema. Os Estados Unidos da América do Norte já eram, então, o País mais respeitado do mundo e se haviam imposto em todos os setores das atividades humanas; isso fez com que para lá convergisse grande quantidade de técnicos com ampla experiência e largos recursos econômicos, pelo que não lhes foi difícil estabelecer Cinema sob novas bases, inteiramente industriais, a que se deveria a maior evolução desse meio de expressão do pensamento. Os competidores europeus, obstados em seu trabalho pela guerra continuada e cruenta, tiveram de ceder terreno: a penetração do filme americano em todos os mercados, mesmo europeus, fez-se, assim, naturalmente, e as plateias vibravam com a ingenuidade cômica de Carlitos ou as façanhas indescritíveis dos heróis do "western"; era, de fato, a segunda idade do Cinema, aquela que Lumière não ousara sonhar, nem Méliès lograra atingir com seu portentoso gênio (SILVA NOBRE, 1955, p. 17-18).

Nessa passagem é perceptível a explicação para um possível malogro da atividade cinematográfica nacional, porém a data é 1914. Essa possibilidade, todavia, é elidida devido ao fato de que o autor não mencionar uma crise de produção - vale ressaltar que a palavra crise nem aparece —, mas sim recheia sua crônica de dados sobre produções cinematográficas nacionais após o início da Primeira Guerra Mundial, mencionando Inocência, filmado por Vítor Capellaro em 1915, e o cinema educativo realizado por Venerando da Graça, o filme Pátria e bandeira, de Antônio Leal, e as películas $O$ guarani e $O$ mulato, ambos dirigidos por Capellaro, e a instalação de uma filial da Paramount no Rio de Janeiro, em 1916.

Com relação a um possível sucesso de público, ou seja, de recepção positiva das películas nacionais, o mais próximo que Nobre passa de associar esse fator a uma harmonia de interesses de toda a cadeia cinematográfica está na seguinte passagem:

A verdade é que muito se fez nos primeiros tempos de nosso Cinema, talvez porque os problemas de então fossem bem mais simples. Os filmes procuravam retratar algo de nosso e poderíamos ter estabelecido uma indústria cinematográfica com caráter nacional, impondo-se perante o mundo. Infelizmente, isso não chegou a acontecer, conquanto o público 
recebesse e aplaudisse nossos filmes da mesma forma que os estrangeiros (SILVA NOBRE, 1955, p. 18).

Diante dessas colocações é pertinente mencionar que Nobre abre brechas para se interpretar os primeiros anos de nosso cinema como frutíferos, porém não há demarcação cronológica dessas atividades que poderiam ensejar uma interpretação de que havia uma articulação aos moldes de uma indústria cinematográfica, mesmo que artesanal, funcionando em terras nacionais. As informações do pesquisador são genéricas, carecem de maior explicação e referências, assim como de um recorte preciso que autentique uma suposta Bela época do cinema nacional.

Em suma, Pequena história do cinema brasileiro (1955), de Francisco Silva Nobre, ao não incorrer no tema do nascimento do cinema brasileiro, tampouco recortar um período do áureo de nossa história cinematográfica nacional, entre 1907 e 1911, conceituando-o de Bela época, demonstra o caráter de crônica de seu enredo, ao menos com relação aos dois motes problematizados. Tal característica abre caminho para nossa demonstração do processo de transposição de crônicas para uma história por parte de Paulo Emílio, que será empreendida mais adiante.

Quatro anos se passam e vem a público em 1959, Introdução ao cinema brasileiro, do crítico, cineasta e militante comunista Alex Viany. Uma análise sumária nos permite enfatizar que, num primeiro momento, Viany expressa as origens da obra e suas complicações para escrita e publicação, posteriormente aprecia historicamente o cinema brasileiro com a descrição de eventos (ordenados temporalmente de acordo com sua ocorrência) e, por fim, aponta minuciosa filmografia de nosso cinema já publicada até então, além de uma lista de profissionais, índices, textos legislativos atinentes ao cinema nacional e um acervo iconográfico expressivo.

A obra de Alex Viany, sem dúvidas, foi o empreendimento mais elaborado surgido no Brasil da década de 1950, quando o assunto versa sobre nossa cinematografia. No entanto, constitui-se em uma incipiente tentativa de reflexão histórica, cujo ponto central focalizava o embate entre a necessidade e as possibilidades de efetivação existencial do cinema brasileiro, bem como a clarividência de sua inviabilidade condicionada pela ocupação do mercado cinematográfico pelo cinema estrangeiro, especialmente o norte-americano.

Apenas uma rápida olhada no trabalho de Viany explicita, de um lado, que seu empreendimento é genérico, pois os eventos aos quais faz menção carecem de maior explicação e interpretação e, de outro, que sua maior preocupação não é com início, 
desenvolvimento ou possível futuro do cinema nacional, mas sim em arrolar dados e eventos na história de nosso cinema sem efetivamente destacar algum mais vultuoso. Tais características primordiais de Introdução ao cinema brasileiro já revelam seu caráter de crônica, porém isso fico mais claro quando o mote do nascimento e o conceito de Bela época é fruto de investigação mais acurada.

Alex Viany, como Francisco Silva Nobre, não menciona o nascimento, pois, se furtando de expor explicitamente o acontecimento, o pesquisador apenas arranja temporalmente na ordem de ocorrência os diversos eventos que poderiam corresponder ao marco. Isso fica claro quando frisa o seguinte: “[...] ninguém conseguiu precisar, até agora, qual foi a primeira filmagem brasileira, podendo-se apenas dizer com certeza que a honra não pertence ao português Antônio Leal [...]" (VIANY, 1959, p. 25).

Como conclui Jean-Claude Bernardet, malgrado a metáfora do nascimento do cinema nacional esteja implícita na obra de $V_{i a n y}{ }^{6}$, o pesquisador não esconde sua ignorância com relação aos primórdios de nosso cinema, não menciona a data de 1898 como nascimento, tampouco usa explicitamente o termo (BERNARDET, 1995, p. 18-19). O mais próximo que chega ao falar dessa datação é quando, ao mencionar a documentação organizada pelo crítico, cineasta e pesquisador já veterano Adhemar Gonzaga, que estava sendo publicada esporadicamente no decorrer da segunda metade do decênio de 1950 no Jornal do Cinema, diz: “Após muitas investigações, garante-nos Ademar Gonzaga que em 1898 já se realizavam filmagens no Brasil” (VIANY, 1959, p. 25).

Acerca do conceito de Bela época, a seu modo, Alex Viany é ainda mais sucinto que Nobre. Ao mencionar o período recortado (1907-1911) pela historiografia clássica, porém retrocedendo à primeira exibição cinematográfica no país, o pesquisador se restringe a dar informações mais genéricas ainda que seu antecessor. Primeiro afirma sem maiores preocupações: "Não se passou muito tempo, desde aquela sessão pública de 8 de julho de 1896, até que diversos brasileiros, e estrangeiros aqui radicados, apaixonando-se pelo invento, saíssem também a filmar por todos os cantos" (VIANY, 1959, p. 25). Em seguida, após delinear a importância do papel desempenhado na divulgação do cinema no Brasil por Aurélio

\footnotetext{
${ }^{6}$ Sobretudo porque o pesquisador pensa o cinema brasileiro com base na metáfora do fluxo de vida humano: Parte I - A INFÂNCIA NÂO FOI RISONHA E FRANCA, com os seguintes capítulos: 1) De como o rapazinho se fez Homem; 2) Um esforço individual: Almeida Fleming; 3) Um surto regional: Campinas; 4) Outro surto regional: Recife; 5) Outro esforço individual: Humberto Mauro; Parte II - NO PRINCÍPIO ERA O VERBO (QUE ATRAPALHAVA), com os capítulos: 6) Onde o rapazinho leva um tombo; 7) Dois diletantes na Indústria: Gonzaga \& Santos; 8) Onde o rapazinho enfrenta crise após Crise; parte III - VIAGEM (COM ESCALAS) À TERRA DE VERA CRUZ; com os capítulos: 9) A visita do filho pródigo; 10) Onde contam os tropeços e se dá uma receita. As palavras escritas em caixa-alta se justificam porque consistem na reprodução fidedigna do texto de Viany.
} 
da Paz dos Reis e Vittorio de Maio, salienta: "De qualquer modo, muitos filmes foram produzidos no Brasil até 1910, em um só rolo, naturalmente, como as produções da época em todo mundo" (VIANY, 1959, p. 28). Por fim, depois de introduzir o leitor aos empreendimentos de Antonio Leal, Francisco Serrador, William Auler, Patrocínio Filho e outros, novamente dando voz a Adhemar Gonzaga, acentua:

Em 1909/10, narra-nos Adhemar Gonzaga, fizemos mais de cem filmes cada ano [...]. "Nesse tempo, o cinema brasileiro não temia a concorrência estrangeira, e nossos filmes realmente atraíam mais atenção do que The Violin Maker of Cremona ou The Lonely Villa, de Griffith. Nosso cinema dava pancada mesmo no que vinha de fora" (VIANY, 1959, p. 33).

Notemos que Viany também sequer utiliza o termo Bela época, muito menos aventa algum tipo de explicação no tocante aos motivos pelos quais "fizemos mais de cem filmes cada ano". A colocação de Gonzaga é tida como verdade autoexplicativa. Esse posicionamento não é inócuo, pois aquilo que importa ao autor não são as explicações explícitas ou mesmo construir algum tipo de conceito, mas sim arrolar os eventos, trazendo o leitor para o fluxo temporal cronológico do cinema nacional. O próprio Alex Viany justificou o caráter lacunar de sua obra, apontando seu desconhecimento sobre os primórdios de nosso cinema, assim como sublinhando sua intenção de apenas lançar o assunto história cinema brasileiro em um livro-piloto (VIANY, 1959, p. 12-14).

Com efeito, fica explícito o fato de que Introdução ao cinema brasileiro (1959), de Alex Viany, constitui-se em uma crônica do cinema nacional, especialmente com relação ao tema do nascimento do cinema brasileiro (de 1898) e ao conceito de Bela época de nossa cinematografia (1907-1911). Tal característica de crônica, ao mesmo tempo em que revela o estágio das pesquisas históricas sobre o cinema nacional no decênio de 1950, nos serve de subsídio para abordar a recepção e resposta a essa condição historiográfica por parte de Paulo Emílio.

\section{A transposição das crônicas para uma história: o nascimento e a Bela época no} Panorama do cinema brasileiro: 1896/1966, de Paulo Emílio

Paulo Emílio não passava alheio à produção historiográfica atinente ao cinema nacional. Em suas críticas no Suplemento Literário d'O Estado de São Paulo, os empreendimentos de Francisco Silva Nobre e Alex Viany receberam tratamento crítico no

Oficina do Historiador, Porto Alegre, EDIPUCRS, v. 7, n. 2, jul./dez. 2014, p. 118-139. 
calor de suas respectivas publicações. Em 17 de novembro de 1956, o crítico revelou sua recepção da obra de Nobre da seguinte maneira:

\begin{abstract}
Apesar de sumário - trata-se de uma acumulação de notas dispostas cronologicamente - o trabalho de Silva Nobre pode ser utilizado como ponto de partida por quem, não dispondo de outro material, queira iniciar o estudo do cinema brasileiro. As lacunas e os erros do livro não são o defeito principal, mas sim a ausência total de referências às fontes de informação (GOMES, 1981, p. 27, vol. 1).
\end{abstract}

A posição do crítico é clara: sua crítica dá ênfase, por um lado, à falta de rigor metodológico, ao menos na citação das fontes - se tornando, para ele, o principal defeito do livro- e, por outro, ao caráter sumário da obra, sobretudo por apenas arrolar dados cronologicamente na ordem de suas ocorrências. Em face dessa postura, podemos notar que Paulo Emílio encara o trabalho de Nobre como uma introdução ao estudo do cinema brasileiro, portanto, uma crônica disponível a quem pretendesse urdir uma história de nosso cinema.

Já a obra de Alex Viany recebeu inúmeras críticas negativas da parte de Paulo Emílio, que a ela dedicou dois artigos. No primeiro, de 30 de janeiro de 1960, embora reconhecendo o livro como "instrumento indispensável de trabalho" aos pesquisadores do cinema nacional, o crítico o encarava como preliminar, insistindo em mencionar a obra como "primeira versão", bem como sugerindo, desde o acréscimo de filmes até uma indexação cronológica de películas ao invés da alfabética (GOMES, 1981, p. 145-148, vol. 2). O trecho no qual Paulo Emílio concluiu sua análise preliminar do livro é importante aos nossos propósitos. Ele pontua:

\footnotetext{
Ao iniciar a leitura do texto propriamente dito, as 170 páginas em que o autor nos fala de coisas que se sucederam durante mais de sessenta anos, desde a chegada do cinema no Brasil em julho de 1896 até as produções brasileiras de 1959, a minha esperança maior era a de que Alex Viany descrevesse o mundo obscuro da velha cinematografia brasileira e fornecesse chaves para a sua compreensão. Devo dizer que o autor me decepcionou e vou explicar por quê (GOMES, 1981, p. 149, vol. 2).
}

Significativamente, essa conclusão abre lastro a uma discussão sobre os motivos dessa decepção, cujas balizas constituem-se em diversos aspectos negativos que o crítico destacou com exatidão em seu segundo artigo dedicado ao livro. Nele, publicado em 6 de fevereiro de 1960, Paulo Emílio explica: 
Possuindo escassa documentação e sem disposição para pesquisas originais, Alex Viany foi levado a apoiar-se no que outros já haviam escrito. Se houvesse fartura de estudos históricos parciais a respeito do cinema brasileiro, sua tarefa seria melhor sucedida. Quando existe abundância de dados colhidos e trabalhados sobre determinado assunto, estes se estruturam, por assim dizer, espontaneamente, diante do historiador, que sente com clareza onde se acham os pontos obscuros, as principais lacunas; e o seu esforço consiste então em reforçar melhor alguns setores de um conjunto que já se tornou coerente. Não é absolutamente o caso com a história do cinema brasileiro. O que já existe de público tem sobretudo valor de pista, sugestão, indicação, estímulo para pesquisas. Satisfazendo-se quase sempre com o que já encontrou esboçado por outrem, Alex Viany não logrou a menor articulação entre os disparatados elementos de informação que tinha ao seu alcance. Introdução ao cinema brasileiro é um livro sem roteiro. Sua técnica de construção é uma montagem bastante livre, cujo único critério é uma frouxa cronologia. Todo o início do primeiro capítulo é praticamente uma súmula dos escritos de Adhemar Gonzaga, entrecortada de alusões ao êxito do cinema no Brasil e aos artistas de mais prestígio, alusões essas colhidas em Marcel Lapierre ou Fernandes Cuenca. Após referências sumárias a fatos certamente de grande significado, como o início das carreiras de Antônio Leal e Francisco Serrador na primeira década do século, o relato de Viany adquire, durante umas poucas páginas, forma e animação, pois está resumindo trechos de um livro de Magalhães Jr. Em seguida, continuam a aparecer subitamente nomes de pessoas e de fitas como se fossem produtos de geração espontânea. Não há situação definida, uma atmosfera recriada, um perfil humano delineado (GOMES, 1981, p. 151-152, vol. 2).

O teor central das críticas de Paulo Emílio a priori parece que foi direcionado à pessoa de Viany, cuja vocação para pesquisa histórica chega a ser colocada sob suspeição. Contudo, a essência primordial do texto que está eclipsada incita a constante preocupação e crítica ao contexto mais amplo do estado geral dos estudos históricos sobre cinema no Brasil, como também remetem ao caráter de crônica da obra de Viany outorgado por Paulo Emílio. O crítico, quando cobra do empreendimento um roteiro, propondo maior animação e forma, criticando o aparecimento de dados, como se fossem produtos de geração espontânea, ensejando uma recriação da atmosfera do cinema brasileiro, a definição de situações e o delineamento de perfis humanos, na verdade, tem em seu ponto de partida uma preocupação acerca da maneira pela qual uma história do cinema brasileiro deveria ser urdida.

De um modo geral, os contornos das problematizações do crítico, especialmente no que é exposto negativamente acerca das obras de Francisco Silva Nobre e Alex Viany se dão em dois níveis: um primeiro que toca na maneira de escrever a história do cinema brasileiro e um segundo que demonstram sua concepção do trabalho do historiador diante de sua documentação. Para Paulo Emílio, a construção de uma história do cinema nacional deveria ser baseada no modelo das grandes sínteses, porém deveria suplantar o caráter geral das

Oficina do Historiador, Porto Alegre, EDIPUCRS, v. 7, n. 2, jul./dez. 2014, p. 118-139. 
crônicas tocantes ao cinema brasileiro da década de 1950, passando por um arranjo hierárquico dos eventos mediante o realce e/ou subordinação de acontecimentos, com vistas a conquistar uma coerência formal de significados de um conjunto de ocorrências ${ }^{7}$. Assim, a postura do crítico vai ao encontro dos procedimentos de narrativização e semantização expostos por Michel de Certeau.

Como visamos demonstrar, através da narrativização Paulo Emílio atribuiu uma cronologia aos dados de que dispunha no momento da urdidura do enredo de sua síntese e por meio da semantização construiu um sistema ordenado de sentido, isto é, uma narrativa convincente acerca do tema do nascimento do cinema brasileiro e do conceito de Bela época, com base empírica/referencial nas crônicas de Nobre e Viany, que traziam a simples descrição desses dados ordenados temporalmente na ordem de suas ocorrências. Vejamos num instante primário o modo pelo qual o crítico elabora o mote do nascimento do cinema brasileiro.

Em seu Panorama do cinema brasileiro: 1896/1966, Paulo Emílio enfatiza:

Em 1898, voltando ele [Afonso Segreto] de uma de suas viagens, tirou algumas vistas da Baía de Guanabara com a câmara de filmar que comprara em Paris. Nesse dia - domingo, 19 de junho - a bordo do paquete francês "Brèsil", nasceu o cinema brasileiro (GOMES, 1980, p. 40).

Depreende-se que, enquanto Alex Viany não se refere explicitamente a um nascimento e Nobre nem se aproxima do termo, tampouco menciona a datação de 1898, Paulo Emílio não abre ressalva e com muita certeza afirma: "neste dia nasceu o cinema brasileiro". Dessa forma, o crítico, ao ratificar o nascimento do cinema nacional com uma filmagem (produção) em detrimento de diversas exibições ou mesmo da distribuição de filmes, elege um evento (filmagem de Segreto em 1898) como mais importante que outros possíveis. Assim, incorre no procedimento de realçar um acontecimento, ao mesmo tempo em que subordina toda a sua história a essa marca de origem, que é pautada na filmagem (produção cinematográfica).

Com efeito, não há como negar que tal procedimento consiste também na transformação de um acontecimento (filmagem) em fato histórico (nascimento). Para Michel de Certeau,

\footnotetext{
${ }^{7}$ Por um lado, tal procedimento se dá em constante diálogo com os ideais propugnados pelos sujeitos inseridos no interior do Instituto Superior de Estudos Brasileiros (ISEB) e no Partido Comunista Brasileiro (PCB), cf. (MORAIS, 2009, p. 1-13). Por outro, também pode ser percebido à luz da diferença de leitura do marxismo por parte de Paulo Emílio e Alex Viany. O primeiro, como demonstra João Carlos Soares Zuin, segue uma vertente independente do marxismo desde sua primeira estadia em Paris, entre 1937 e 1939, cf. (ZUIN, 2001, p. 107-125; , 2002). Já o segundo, conforme expressa Arthur Autran Franco Sá Neto, no período em que urde sua obra, é militante do PCB e segue as diretrizes do partido, cf. (SÁ NETO, 2003).
} 
[...] o acontecimento é aquele que recorta, para que haja inteligibilidade; o fato histórico é aquele que preenche para que haja enunciados de sentido. $\mathrm{O}$ primeiro condiciona a organização do discurso; o segundo fornece os significantes, destinados a formar, de maneira narrativa, uma série de elementos significativos. Em suma, o primeiro articula, e o segundo soletra (CERTEAU, 2007, p. 103).

À luz dessa asserção percebemos que existe de modo explícito no Panorama a eleição de um acontecimento (filmagem) para que haja inteligibilidade e, concomitantemente, condicione a organização do discurso de Paulo Emílio. Tornado fato histórico (nascimento), ele preenche de sentido a narrativa do crítico para que haja uma série de elementos significativos em sua história. Portanto, a filmagem (acontecimento) plasmada em fato histórico (nascimento) condiciona a organização do discurso pela via da produção cinematográfica, na medida em que se transforma num marco importante a ser debatido no espaço de experiência no qual o crítico estava inserido, bem como atende ao horizonte de expectativas daqueles que se depararam com sua síntese histórica na década de $1960^{8}$.

Jean-Claude Bernardet chama a atenção para o fato segundo o qual a escolha de uma filmagem, ou seja, da produção cinematográfica para marcar o nascimento de nossa cinematografia em 1898, constitui-se numa profissão de fé ideológica, pois funcionou como uma resposta à cadeia exibidora, que era monopolizada pelos filmes estrangeiros (BERNARDET, 1995, p. 26-27). Com base nisso, pode-se avaliar que numa conjuntura histórica na qual o mercado exibidor brasileiro é dominado por filmes estrangeiros, não convinha aos pares de Paulo Emílio tomar contato com uma história do cinema nacional escrita pela via da exibição ou mesmo da distribuição de filmes, na medida em que essas não eram necessariamente consideradas expressões de nossa nacionalidade cinematográfica ${ }^{9}$.

\footnotetext{
${ }^{8}$ Na perspectiva de Reinhart Koselleck, "espaço de experiência” pode ser entendido como o passado tornado atual no momento da construção intelectual presente, no qual convivem, ao mesmo tempo, vários tempos anteriores que são preservados na memória e incorporados no cotidiano. Por outro lado, horizonte de expectativas pode ser observado como aquilo que está nas aspirações presentes, porém visando o futuro, cf. (KOSELLECK, 2006).

${ }^{9}$ No Panorama, ao falar da $1^{a}$ época (1896-1912), Paulo Emílio passa rapidamente pelas inúmeras exibições ocorridas na capital federal até 1898, dando maior destaque ao suposto nascimento do cinema brasileiro — uma filmagem, logo, constituinte do processo de produção cinematográfica - e ao período da Bela época, sobretudo às inúmeras produções surgidas no período. Na $2^{a}$ época (1912-1922) o foco também recai sobre a produção, pois são destacados os papéis de "cineastas" na produção cinematográfica, como Luiz de Barros, no Rio de Janeiro, José Medina, em São Paulo, Vitório Capellaro e Antônio Leal. Na $3^{a}$ época (1923-1933), ancorado na ideia-chave segundo a qual a imprensa cinematográfica, sobretudo as revistas Paratodos e Selecta, teve um papel de excessiva importância num "novo fôlego" da produção cinematográfica, bem como destacando que nesse período a produção chegou ao dobro da do período precedente (quase 120 filmes), o crítico novamente atribuiu exclusividade à produção, especialmente ao destacar detalhadamente ciclos de produção além de Rio de Janeiro e São Paulo, como os de Minas Gerais, Rio Grande do Sul, Pernambuco e Campinas. Na 4ª́poca (1933-1949), a
} 
$\mathrm{Na}$ esteira desses argumentos, nota-se que Paulo Emílio constrói uma história do cinema brasileiro com base no recorte da produção cinematográfica, que é condicionado pela eleição de um determinado acontecimento (filmagem/produção de Segreto) e sua transformação em fato histórico (nascimento). Esses fatores ditam os rumos de sua síntese histórica, demonstrando que suas escolhas são diferentes daquelas adotadas por Francisco Silva Nobre e Alex Viany - que buscavam expor em tela o maior número possível de informações, sem se ater a determinado espectro do campo cinematográfico, muito menos urdir o enredo sobre algum gênero específico.

À luz do conceito de nascimento e sua imposição de um recorte que privilegia a produção de filmes, o crítico constrói um texto coerente com o interesse de um grupo de produtores, diretores e críticos que lutavam por um lugar ao sol nas décadas de 1950 e 1960, sendo esse sol a metáfora do processo de distribuição e exibição do cinema nacional. Ao mesmo tempo, sua síntese histórica segue os rumos ditados pela necessária reposição utópica de uma Bela época do cinema brasileiro, que sensivelmente pleiteia uma leitura seletiva do passado, com vistas à construção de um futuro constituído de uma nova Bela época, moderna em termos industriais e constituída preferivelmente por películas de conteúdo nacional.

Assim, a adesão e a reelaboração do conceito de Bela época constituem-se noutro elemento - agora uma codificação de conceitos para explicar e interpretar um recorte periódico de determinados eventos - que atribui à síntese histórica urdida por Paulo Emílio o caráter de história e às obras de Silva Nobre e Alex Viany o status de crônica. Como já ressaltado ao longo desse texto, a Bela época do cinema brasileiro é recortada no Panorama do cinema brasileiro: 1896/1966 pelo período que vai de 1907 a 1911, no qual supostamente houve uma harmonia de interesses entre produção, distribuição e exibição de filmes no país.

Com base nessa premissa, o crítico urde o enredo de uma história apoiando-se nos dados presentes nas iniciativas de Francisco Silva Nobre e Alex Viany, porém, como enfatiza Jean-Claude Bernardet, acentua o período em consonância com os interesses de criação de um tempo nostálgico que deveria ser reconquistado no fluxo histórico, à maneira de um tempo mítico do passado que também era uma utopia de futuro (BERNARDET, 1995, p. 40-41).

produção mais uma vez dita a urdidura do enredo, no qual são destacadas ações de Gilberto Rossi, Oduvaldo Vianna e Humberto Mauro, além do surgimento de produtoras, como Cinédia e Atlântida Cinematográfica. Por fim, na $5^{a}$ época, a produção cinematográfica paulista (Companhia Cinematográfica Vera Cruz, Maristela e Multifilmes), as produções mais independentes (efetuadas por Nelson Pereira dos Santos e Walter Hugo Khouri) e os filmes cinemanovistas marcam uma história totalmente moldada pelo recorte da produção de longasmetragens ficcionais. 
Perseguindo esse propósito, além de lançar a público o conceito de Bela época ${ }^{10}$, Paulo Emílio explica e interpreta o sucesso e declínio desse período, de modo a compor um quadro teleológico que é inexistente nas propostas anteriores.

Quando acentua os motivos do início e florescimento do período, o crítico pontua:

Os dez primeiros anos de cinema no Brasil são paupérrimos. As salas fixas de projeção são poucas, e praticamente limitadas a Rio e São Paulo, sendo que numerosos cinemas ambulantes não alteravam muito a fisionomia de um mercado de pouca significação. A justificativa principal para o ritmo extremamente lento com que se desenvolveu o comércio cinematográfico de 1896 a 1906 deve ser procurada no atraso brasileiro em matéria de eletricidade. A utilização, em março de 1907, da energia produzida pela usina do Ribeirão das Lages teve consequências imediatas para o cinema no Rio de Janeiro. Em poucos meses foram instaladas umas vinte salas de exibição [...] Esse subido florescimento do comércio cinematográfico em 1907 influiu diretamente na produção de filmes brasileiros [...] alguns dos novos empresários cinematográficos procuraram se dedicar simultaneamente à importação, exibição e produção de filmes [...] Tal entrosamento entre o comércio de exibição cinematográfico e a fabricação de filmes explica a singular vitalidade do cinema brasileiro entre 1908 e 1911 (GOMES, 1980, p. 41-42).

Ao contrário das crônicas de Francisco Silva Nobre, cuja datação é inexata quanto ao recorte e informações sobre sucesso ou não do período, e de Alex Viany, que somente aponta o contexto como um momento áureo na história do cinema brasileiro, Paulo Emílio atribui à maior distribuição de energia elétrica o marco de início da Bela época, enquanto que do entrosamento entre produção, distribuição, exibição advém o sucesso do período. Nessa empresa, o crítico estabelece um marco inicial devido somente a um acontecimento, bem como reafirma uma suposta harmonia entre todas as esferas cinematográficas, que automaticamente se torna uma utopia a ser reconquistada no cinema nacional. Desse modo, sem sua síntese histórica, cuja característica de história advém necessariamente da utilização dos dados de crônicas de Silva Nobre e Viany, novamente ocorre o realce de apenas um acontecimento (utilização da energia produzida pela usina Ribeirão das Lages) e a subordinação de outros a ele, como o fato do surgimento de salas de exibição e interesse de produtores e exibidores em também produzir filmes.

\footnotetext{
${ }^{10}$ Cabe ressaltar que uma pesquisa específica sobra a Bela época do cinema brasileiro, no período em que Paulo Emílio urde o Panorama, já vinha sendo empreendida por Vicente de Paula Araújo. No entanto, a pesquisa em voga, intitulada A Bela época do cinema brasileiro, apesar de passar pelas mãos de Paulo Emílio nesse contexto, somente seria lançada em 1976, cf. (ARAÚJO, 1976).
}

Oficina do Historiador, Porto Alegre, EDIPUCRS, v. 7, n. 2, jul./dez. 2014, p. 118-139. 
A explicação para o término da Bela época também é fruto de um processo de adequação de informações das crônicas, isto é, sua transposição em uma história. Em sua narrativa, Paulo Emílio afirma o seguinte:

\begin{abstract}
Encerrava-se assim, em meados de 1911, um ciclo particularmente movimentado, talvez brilhante mesmo do cinema nacional. [...] Intensificava-se a crise: quase todos aqueles que participavam ativamente da fabricação de filmes nacionais abandonam as lides cinematográficas. Argumentistas, roteiristas e diretores de cena que haviam surgido, aos poucos vão retornando às suas origens jornalísticas e teatrais. O desinteresse generalizado atinge também os primeiros produtores [...] Agrava-se a deserção: Labanca abandona definitivamente a profissão cinematográfica. Permanece Serrador, mas sua frutuosa carreira no cinema apoia-se agora exclusivamente no comércio do filme produzido no estrangeiro. Rompe-se a antiga solidariedade de interesses entre os fabricantes de filmes nacionais e o comércio local de cinematografia. Os que persistem em fazer filmes nacionais encontram crescente dificuldade em exibi-los (GOMES, 1980, p. 41).
\end{abstract}

Esses argumentos, em um primeiro nível, não são de todo novidade. Francisco Serrador, dono da Cia. Cinematográfica Brasileira, é mencionado, o comércio nacional volta os olhos para os filmes estrangeiros e o termo crise constitui-se numa pedra-de-toque. Temos a reprodução das passagens mais ricas das pesquisas de Nobre e Viany, porém reformuladas. No outro nível é notória a explicação de Paulo Emílio com base na categoria histórica subdesenvolvimento $^{11}$, bem como a articulação disso com a construção temporal de uma idade mítica a ser alcançada no fluxo histórico nacional. Isso fica bastante explícito quando o crítico finaliza seu Panorama enfatizando a necessidade de se reconquistar, em modernos termos industriais, a solidariedade de interesses entre os donos das salas de cinema e os fabricantes de filmes nacionais que existiu no país em 1910 (GOMES, 1980, p. 79).

Com efeito, no contexto em que Paulo Emílio urde sua história - de modernização cultural, de impulso industrial e outras inovações — o passado (a Bela época) deixa de ser padrão para o presente e torna-se na melhor das hipóteses um modelo, porém como máscara para inovação e por meio de uma seleção. Tal perspectiva é encaminhada via (re)elaboração

\footnotetext{
${ }^{11}$ Utilizamos a noção de categoria histórica pautando-nos nas proposições do teórico alemão Jörn Rüsen. De acordo com ele, as categorias históricas "[...] designam contextos temporais gerais de estados de coisas, com base nos quais estes aparecem como históricos. Não se referem diretamente a nenhum estado de coisas, mas estabelecem a qualidade histórica da mudança temporal dos estados de coisas. Na maioria dos casos, essa qualidade não é conferida aos estados de coisas pelas fontes, mas é-lhes atribuída pela atividade cognitiva dos historiadores" (RÜSEN, 2010, p. 93). Com relação ao subdesenvolvimento, sobretudo acerca da maneira pela qual Paulo Emílio utiliza essa categoria histórica em sua obra, tornando-se uma matriz interpretativa dos trabalhos que aplicam o subdesenvolvimento à nossa experiência cinematográfica, cf. (MORAIS, 2010a, p. 196$205 ; \ldots$ _ 2010c, p. 173-186).
} 
de dados das crônicas, bem como pensando a Bela época do cinema brasileiro como um momento que deve ser reposto no futuro cinematográfico nacional: em modernos termos industriais.

Em suma, é uma Bela época vivida no passado que ilumina o caminho para o futuro. Portanto a síntese histórica de Paulo Emílio reelabora o tempo histórico do cinema brasileiro com base nesse conceito e de acordo com o horizonte de expectativas de grande parcela da intelectualidade cinematográfica brasileira dos decênios de 1950 e 1960. Essa expectativa pauta-se na negação do status quo subdesenvolvido, cuja característica básica é a dominação/ocupação do mercado interno pelo produto estrangeiro, ensejando um tipo de leitura seletiva do passado. Portanto, a história de Paulo Emílio reserva às obras de Francisco Silva Nobre e Alex Viany o lugar de crônicas, pois é edificado um sistema de sentido no qual o passado e o presente do cinema brasileiro são fundamentalmente marcados pela ocupação de nosso mercado pelo filme estrangeiro, mas a tal ocupação é reservado um futuro no qual se reconquistará, em modernos termos industriais, uma nova Bela época, cuja tão almejada harmonia de interesses entre as esferas da produção e da exibição cinematográficas é condição sine qua non.

\section{À guisa de conclusão}

Perante às discussões travadas nesse artigo percebe-se que, ao discutir o tema do nascimento do cinema brasileiro e o conceito de Bela época de nossa cinematografia, Paulo Emílio constrói uma síntese histórica do cinema brasileiro em seu Panorama com características de história, ao contrário de Francisco Silva Nobre e Alex Viany, cujas obras carregam os traços característicos de crônica. Nessa medida, percebemos a maneira pela qual o crítico utiliza os postulados apontados por Michel Certeau no relacionamento de uma narrativa com as crônicas. A saber: uma semantização referencial, uma transcritibilidade das linguagens já codificadas e a construção de uma metalinguagem na própria língua dos documentos utilizados.

Dessa maneira, a semantização referencial, que vem da própria cultura na qual Paulo Emílio está inserido, pode ser encontrada no próprio arquétipo formal de seu ensaio, que traz consigo uma concepção marxista de história, sobretudo com base numa visão teleológica. Nesse sentido, a história da cinematografia nacional na síntese urdida pelo crítico obedece à

Oficina do Historiador, Porto Alegre, EDIPUCRS, v. 7, n. 2, jul./dez. 2014, p. 118-139. 
economia da produção dos filmes, bem como segue aos rumos ditados pelo conceito Bela época - denominador do período cinematográfico nacional que vai de 1907 a 1911, considerado frutífero em termos de harmonia entre produção, distribuição e exibição — e sua necessária reposição utópica, condicionante de etapas degradadas no decorrer do fluxo histórico. Em poucas palavras, é um período histórico considerado áureo dos primórdios do cinema brasileiro que retornará no tempo histórico cíclico, cuja inevitabilidade é uma certeza absoluta via perspectiva teleológica.

Assim, Paulo Emílio se adequa ao espaço de experiência em que urde sua história, bem como ao horizonte de expectativas de grande parte dos sujeitos ligados à produção cinematográfica nacional. No espaço de experiência da década de 1960, permeado pelas discussões sobre nacionalidade e luta contra o status quo subdesenvolvido, a valorização da produção cinematográfica brasileira (sobretudo cinemanovista) é tomada como defesa da invasão dos filmes estrangeiros em nosso mercado interno (MORAIS, 2010c, p. 173-186). Nesse sentido, o crítico urde seu enredo em consonância com um horizonte de expectativas dos cineastas nacionais que projetam um futuro do cinema brasileiro no qual nossas produções serão hegemônicas no mercado exibidor, bem como expressarão a "legítima" cultura nacional.

No tocante à transcritibilidade das linguagens já codificadas, a síntese histórica de Paulo Emílio é explícita. Embora se furte de vincular a história de nossa cinematografia à nossa história social, como ressalta Jean-Claude Bernardet, Paulo Emílio segue o método clássico de escrever a história do cinema, seja mundial ou nacional, por meio de uma periodização que valoriza eventos na ordem de suas ocorrências, pois sem uma tradição cinematográfica já constituída, o crítico teve que recorrer ao modelo clássico de se urdir um enredo acerca de uma história cinematográfica (BERNARDET, 1995, p. 53). No entanto, o fator diferencial é o procedimento que isola os dados nacionais cinematográficos e hierarquiza eventos no processo histórico, como ocorre no caso do nascimento e da Bela época, explicando-os e interpretando-os, de modo a relacionar-se internamente com as crônicas de cinema brasileiro, porém não apenas reproduzindo-as. Esse caso é explícito no recorte que privilegia a produção cinematográfica de longas-metragens ficcionais, como também na postura de enfrentamento à invasão do mercado interno pelos filmes estrangeiros.

Por fim, a metalinguagem na própria língua dos documentos utilizados ocorre, na medida em que percebemos, à luz da cronologia e dos eventos mencionados nas crônicas de Silva Nobre e Alex Viany, a utilização e construção do tema do nascimento do cinema brasileiro e do conceito de Bela época por parte de Paulo Emílio. Dito de outra maneira,

Oficina do Historiador, Porto Alegre, EDIPUCRS, v. 7, n. 2, jul./dez. 2014, p. 118-139. 
nascimento e Bela época são construídos sob uma ótica bastante particular, com vistas a urdir um enredo de maneira convincente e taxativa, pois promovem um sistema edificado de sentido em consonância com o espaço de experiência no qual o crítico está inserido (década de 1960) e com o horizonte de expectativas de grande parcela dos cineastas nacionais do período, sobretudo cinemanovistas.

Dessa forma, a história de Paulo Emílio, sobretudo no tocante ao nascimento e à Bela época, dialoga diretamente com seu público leitor, composto de gente ligada ao cinema nacional que sofria diretamente com uma distribuição e exibição cinematográfica monopolizada pelo cinema estrangeiro, sobretudo norte-americano. Assim, nada mais coerente para a edificação do sistema de sentido, o procedimento no qual Paulo Emílio explica e interpreta a história de nosso cinema plasmando em fato (nascimento) um acontecimento (filmagem de Afonso Segreto), bem como elaborando o conceito de Bela época com base numa visão teleológica da história. Por meio dessa iniciativa, o crítico consegue estabelecer um contrato enunciativo entre remetente e destinatário, no qual a relação com o passado cinematográfico nacional é ratificada pela prática de seu presente e visa, ao mesmo tempo, com a representação e a performatividade, dar uma lição, pois, como frisa Michel de Certeau:

A historiografia se serve da morte para ratificar uma lei (do presente). Ela
não descreve as práticas silenciosas que a constroem, mas efetua uma nova
distribuição de práticas já semantizadas. Operação de uma outra ordem que a
da pesquisa. Pela sua narratividade, ela fornece à morte uma representação
que, instalando a falta na linguagem, fora da existência, tem valor de
exorcismo contra a angústia. Mas, por sua performatividade, preenche a
lacuna que ela representa, utiliza este lugar para impor um querer, um saber
e uma lição ao destinatário. Em suma, a narratividade que oculta, metáfora
de um performativo, encontra apoio, precisamente, naquilo que oculta: os
mortos, dos quais fala, se tornam vocabulário de uma tarefa a empreender
(CERTEAU, 2007, p. 108).

A par desse argumento, pode-se afirmar que a síntese histórica urdida por Paulo Emílio procura sepultar um morto (o passado do cinema brasileiro), mas, ao mesmo tempo, utiliza-se da sua falta e denota uma tarefa a ser executada: a construção de um cinema brasileiro que, apesar da estrutura econômica subdesenvolvida, seja capaz de expressar em suas produções cinematográficas a realidade nacional ${ }^{12}$.

\footnotetext{
12 Tal intento de Paulo Emílio promove o diálogo de sua obra com as perspectivas expressas pelos cineastas do movimento cinemanovista, cf. (MORAIS, 2010a, p. 153-181; , 2010d, p. 45-68).
} 
Em última instância, com base no exposto, nota-se que o crítico, em posse das crônicas atinentes ao cinema brasileiro, ao lançar a público o tema do nascimento do cinema brasileiro e o conceito de Bela época ${ }^{13}$ de nossa história cinematográfica, recorre aos movimentos de narrativização e semantização para edificar sua história no Panorama do cinema brasileiro: 1896/1966. Desse modo, Paulo Emílio promove a transposição de crônicas para uma história do cinema brasileiro, que se constituiu em matriz interpretativa da história do cinema brasileiro, pois diversos estudiosos passaram a se alicerçar nela, reproduzindo-a e difundindo-a (MORAIS, 2010a) $)^{14}$.

\section{REFERÊNCIAS BIBLIOGRÁFICAS}

ARAÚJO, Vicente de Paula. A Bela época do cinema brasileiro. São Paulo: Perspectiva, 1976.

BERNADET, Jean-Claude. Historiografia clássica do cinema brasileiro: metodologia e pedagogia. São Paulo: Annablume, 1995.

CERTEAU, Michel de. A escrita da história. Rio de Janeiro: Forense-Universitária, 2007.

GOMES, Paulo Emílio Salles. Panorama do cinema brasileiro: 1896/1966. In:

Cinema: trajetória no subdesenvolvimento. Rio de Janeiro: Paz e Terra, 1980, p. 35-79.

Crítica de cinema no suplemento literário. Rio de Janeiro: Paz e Terra, 1981. 2 volumes.

KOSELLECK, Reinhart. Futuro passado: para uma semântica dos tempos presentes. Rio de Janeiro: Contraponto, 2006.

MORAIS, Julierme. Eficácia política de uma crítica: Paulo Emílio Salles Gomes a constituição de uma teia interpretativa da história do cinema brasileiro. Uberlândia: Dissertação de Mestrado, Programa de Pós-Graduação em História, Universidade Federal de Uberlândia, 2010a.

A historiografia clássica do cinema nacional e a Bela época do cinema brasileiro: a influência de Paulo Emílio Salles Gomes. Fênix - Revista de História e Estudos Culturais.

\footnotetext{
13 Tanto o nascimento quanto a Bela época tornaram-se consenso entre os pesquisadores da história do cinema brasileiro, sendo o Panorama de Paulo Emílio a matriz interpretativa, cf. (MORAIS, 2010a, p. 185-195; , 2010b, p. 1-11).

${ }^{14}$ A discussão sobre a formação dessa matriz extrapolaria os limites desse artigo. Em vista disso, fica a sugestão de leitura sobre isso, cf. (MORAIS, 2010a).
}

Oficina do Historiador, Porto Alegre, EDIPUCRS, v. 7, n. 2, jul./dez. 2014, p. 118-139. 
Uberlândia, Vol. 7, Ano VII, nº 3 Set/Out/Nov/Dez de 2010b, p. 1-11. Disponível em: www.revistafenix.pro.br.

Cinema: trajetória no subdesenvolvimento, de Paulo Emílio Salles Gomes: profícua interlocução ideológica com ISEB e PCB. Fênix - Revista de História e Estudos Culturais. Uberlândia, Vol. 6, Ano VI, $\mathrm{n}^{\circ}$. 4, Out/Nov/Dez de 2009, p. 1-13. Disponível em: www.revistafenix.pro.br.

O conceito de subdesenvolvimento na historiografia clássica do cinema brasileiro e a matriz Paulo Emílio Salles Gomes. Fato \& Versões, vol. 2, nº. 3, 2010c, p. 173-186. Disponível em: www.catolicaonline.com.br/fatoeversoes.

Paulo Emílio Salles Gomes e a adesão ao cinemanovismo: matriz intelectual nas congruências entre Cinema Novo e modernismo literário. In: CAPEL, Heloísa S. F.; PATRIOTA, Rosangela; RAMOS, Alcides F (Org.). Criações artísticas, representações da história: diálogos entre arte e sociedade. São Paulo: Hucitec, Goiânia: Editora da PUC Goiás, 2010d, p. 45-68.

RÜSEN, Jörn. Reconstrução do passado - Teoria da História II: os princípios da pesquisa histórica. Trad. Asta-Rose Alcaide e Estevão de Rezende Martins. Brasília: Ed. da UNB, 2010 .

SÁ NETO, Arthur Autran F. Alex Viany: crítico e historiador. São Paulo: Perspectiva, 2003.

NOBRE, Francisco Silva. Pequena história do cinema brasileiro. Rio de Janeiro: Associação Atlética Banco do Brasil, 1955.

VIANY, Alex. Introdução ao Cinema Brasileiro. Instituto Nacional do livro, 1959.

ZUIN, João Carlos Soares. Empenho político e cultural em Paulo Emílio Salles Gomes. Revista de Sociologia e Política, $\mathrm{n}^{\circ}$. 17, novembro de 2001, p. 107-125.

Paulo Emílio Sales Gomes e Paris: política e cinema como duas vocações. Novos Rumos, ano 17, n. 36, 2002, s/p.

ARTIGO ENVIADO EM: 14/04/2014

ACEITO PARA PUBLICAÇÃO EM: 22/10/2014 